\title{
4-(3-metil-3-fenilsiklobütil)-2-(2-(piridin-4-ylmetilen)hidrazinil) tiyazol'un Sentezi, Karakterizasyonu, Kristalografik Yapısı ve Hirshfeld Yüzeyinin İncelenmesi
}

Fatih ŞEN ${ }^{1}$

ÖZET: $\mathrm{Bu}$ çalışmada, 4-(3-metil-3-fenilsiklobütil)-2-(2-(piridin-4-ylmetilen)hidrazinil)tiyazol $\quad\left[\mathrm{C}_{20} \mathrm{H}_{20} \mathrm{~N}_{4} \mathrm{~S}\right]$ molekülü sentezlendi ve IR, ${ }^{1} \mathrm{H}$ NMR ${ }^{13} \mathrm{C}$ NMR spektroskopileri ile karakterize edildi. Kristalografik ve moleküler yapısı tek kristal X-1şınları kırınımı tekniği ile belirlenmiştir. Bileşik ortorombik P 212121 uzay grubu ile kristalleşmiştir ve birim hücre parametreleri $a=6.208(5) \AA, b=15.938(5) \AA, c=19.573(5) \AA$ ve $\alpha=\beta=\gamma=90.00^{\circ}$ 'dır. Bileşiğin moleküller yapısındaki önemli etkileşimleri belirleyebilmek için PLATON ve Crystal Explorer programları kullanılmış ve kristal örgüsündeki moleküllerin paketlenmesinin doğası anlaşılmaya çalışılmıştır.

Anahtar Kelimeler: Hirshfeld yüzeyi, siklobütan, x-1şını kırınımı

\section{Synthesis, characterization, crystallographic structure and investigation of Hirshfeld surface of 4-(3-methyl-3- phenylcyclobutyl)-2-(2-(pyridin-4-ylmethylene)hydrazinyl)thiazole}

\begin{abstract}
In this study, the title compound 4-(3-methyl-3-phenylcyclobutyl)-2-(2-(pyridin-4-ylmethylene) hydrazinyl)thiazole $\left[\mathrm{C}_{20} \mathrm{H}_{20} \mathrm{~N}_{4} \mathrm{~S}\right]$ was synthesized, characterized with IR, ${ }^{1} \mathrm{H}$ NMR ${ }^{13} \mathrm{C}$ NMR. Crystallographic and molecular structure determined by single-crystal $\mathrm{X}$-ray diffraction techniques. The compound was crystallized in the orthorhombic space group P 212121 with $a=6.208(5) \AA, b=15.938(5) \AA, c=19.573(5) \AA$, and $\alpha=\beta=\gamma=90.00^{\circ}$. PLATON and Crystal Explorer programs were used to determine the remarkable interactions between the molecules and the nature of packing the molecules in the crystal has been tried to be understood.
\end{abstract}

Keywords: Cyclobutane, Hirshfeld surface, $\mathrm{x}$-ray diffraction

Fatih ŞEN (0000-0003-1593-8483), Bozok University, Sorgun Vocational School, Optician, Yozgat, Türkiye

Sorumlu yazar/Corresponding Author: Fatih ŞEN, fatihsen55@gmail.com 


\section{GIRIŞ}

Bileşikler, yapılarında bulundurdukları molekül gruplarının biyolojik ve farmakolojik etkileriyle tıp ve eczacılık gibi birçok alanda kullanılabilmektedir. Bu önemi dikkate alındığında, özellikle ilaç sanayisinde kullanılması öngörülen bileşiklerin sentezlenmesi büyük önem taşımaktadır. Siklobütan türevlerinin anti-inflamatuar (iltihap önleyici) ve anti-depresan (depresyon önleyici) (Dehmlow and Schmidt, 1990), tiyazol türevlerinin antifungal (mantar karşıtı) (Chimenti et al., 2007; Narayana et al., 2004), anti-kanser (Lesyk et al., 2007; Lesyk et al., 2006), anti-inflamatuar (Hassan, 2012), anti-bakteriyel (Ghasemi et al., 2015), anti-konvülsan (Bachir et al., 1990), anti-tüberküloz (Lu et al., 2012), anti-mikrobiyal (Karegoudar et al., 2008; Meral ve Leyla, 2017; Liaras et al., 2011), analjezik (ağrı kesici) (Saravanan et al., 2011; Thore et al., 2013), anti-oksidan (Jaishree et al., 2012), Schiff bazı türevlerinin antitumor ve anti-kanser (Zhou et al., 2007; Utreja et al., 2015), anti-fungal ve antibakteriyel (Prasad et al., 2013; Joseyphus and Nair, 2008), anti-mikrobiyal (Silva et al., 2011), anti-oksidan (Şen ve ark., 2017) ve piridinli bileşiklerin anti-kanser (Mohamed et al., 2012; Abbas et al., 2015), anti-viral (Gueiffier et al., 1998), anti-konvülsan (Pradhan and Goyal, 2016; Salam et al., 2013), anti-mikrobiyal (Abbas et al., 2015; Bhardwaj et al., 2012) ve anti-fungal (Rajput et al., 2011) aktivitelere sahip olduğu bilinmektedir. Bu biyolojik ve farmakolojik etkileri sebebiyle yapısında siklobütan, tiyazol, Schiff bazı ve piridin bulunduran bileşiklerin özellikle ilaç sanayisinde kullanılması öngörülmektedir. $\mathrm{Bu}$ amaçla, literatürde bulunmayan 4-(3-metil-3-fenilsiklobütil)-2-(2-(piridin4-ylmetilen)hidrazinil)tiyazol bileşiği sentezlenmiştir. Bileşiğin moleküler ve kristalografik yapısı tek-kristal X1şını kırınımı yöntemiyle aydınlatılmıştır. Kristali oluşturan molekülleri bir arada tutan hidrojen bağ etkileşimleri incelenmiş Hirshfeld yüzey analizi yöntemiyle moleküler paketlenme anlaşılmaya çalışılmıştır.

\section{MATERYAL VE YÖNTEM}

\section{Kristalin Sentezi}

Bileşik uygun başlangıç materyalleri ve miktarları kullanılarak literatürde (Şen ve ark., 2015) verilen yöntem ile sentezlenip asetondan kristallendirildi. Verim : $\% 76$. Erime noktasi: $478 \mathrm{~K}\left(\mathrm{Et}_{2} \mathrm{O}\right)$. IR $\left(\mathrm{KBr}, v \mathrm{~cm}^{-1}\right): 3138$ (-NH-), 3062 (Aromatik), 2975-2855 (alifatik), 1577 $(\mathrm{C}=\mathrm{N}), 701$ (C-S-C). ${ }^{1} \mathrm{H}$ NMR $\left(\mathrm{CDCl}_{3}\right.$, TMS, $\left.\delta \mathrm{ppm}\right)$ : 1.55 (s, 3H,- $\mathrm{CH}_{3}$, siklobütan), 2.52-2.55 (m, 4H, $\mathrm{CH}_{2}-$ siklobütan), 3.78 (quint, $j=8.8 \mathrm{~Hz}, 1 \mathrm{H},>\mathrm{CH}-$ siklobütan), 6.28 (s, $1 \mathrm{H}$, tiyazol), 7.17-7.19 (m, 3H, aromatik), 7.31$7.36\left(\mathrm{~m}, 2 \mathrm{H}\right.$, aromatik), $7.50\left(\mathrm{dd}, j_{1}=1.2 \mathrm{~Hz}, j_{2}=4.0 \mathrm{~Hz}, 2 \mathrm{H}\right.$, aromatik piridin), 7.73 (s, $1 \mathrm{H},-\mathrm{N}=\mathrm{CH}-$, azometin), 8.65 (dd, $j_{1}=1.2 \mathrm{~Hz}, j_{2}=4.0 \mathrm{~Hz}, 2 \mathrm{H}$, aromatik piridin). ${ }^{13} \mathrm{C} \mathrm{NMR}$ (CDCl $\left.{ }_{3}, \mathrm{TMS}, \delta \mathrm{ppm}\right): 168.26,155.83,152.15,150.25$, $141.53,138.10,128.28,125.43,124.70,120.49,102.86$, $40.23,38.89,30.69,30.23$.

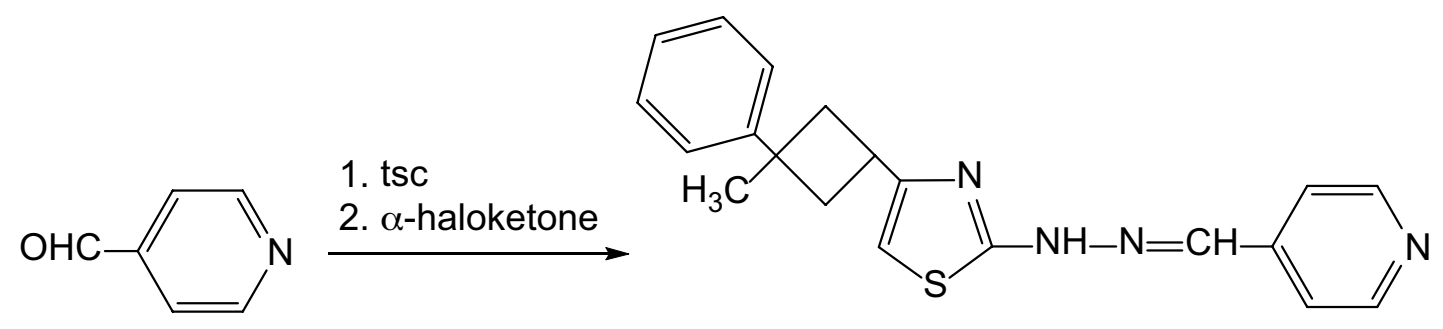

Şema 1. $\left[\mathrm{C}_{20} \mathrm{H}_{20} \mathrm{~N}_{4} \mathrm{~S}\right]$ Kristalinin Sentez Şeması

\section{X - Işımı Kırınımı}

Boyutları $0.25 \times 0.27 \times 0.31 \mathrm{~mm}$ olan bileşiğin kırmızı renkli tek kristalinin $X-1$ şını datası Bruker APEX-II CCD difraktometresi ile $0.71073 \AA$ dalga boylu MoKa sşınları kullanılarak oda sıcaklığında (296 $\left.{ }^{\circ} \mathrm{K}\right)$ toplanmıştır. Veri toplama ve indirgeme süreçlerinde sirasiyla X-AREA ve X-RED (Stoe and Cie, 2002) programları kullanılmıştır. Toplam 29799 yansımanın 4646'sı bağımsız yansımadır. Bu bağımsız yansımalara soğurma düzeltmesi uygulandıktan sonra $\mathrm{I}>2 \sigma(\mathrm{I})$ koşulunu sağlayan 3693 yansıma gözlenen yansıma olarak belirlenmiştir. Gözlenen yansımalar kullanılarak
WinGX (Farrugia, 1999) programı içerisinde bulunan SHELXS 97 (Sheldrick, 1997) yapı çözümleme yazılımı ile direkt yöntemler kullanılarak yapı çözülmüsşür. Fourier haritasında bulunan ağır atomlara ait şiddetli pikler isimlendirilerek hidrojen haricindeki tüm atomların konumları belirlendikten sonra en küçük kareler yöntemi ile arıtım işlemi yapılmıştır (Sheldrick, 1997). Arıtım işleminin ilk aşamasında sıcaklık titreşim parametreleri izotropik alınmıştır. Hidrojen atomları bulunmadan önce sicaklık parametrelerini optimize etmek için hidrojen dışındaki atomlara anizotropik arıtım uygulanmıştır. Sonrasında hidrojen atomları 
geometrik olarak yerleştirilirken aromatik $\mathrm{C}-\mathrm{H}$ bağ uzunlukları $0.93 \AA$ A, metilen $\mathrm{C}-\mathrm{H}_{2}$ bağ uzunlukları $0.97 \AA$, metil $\mathrm{C}-\mathrm{H}_{3}$ bağ uzunluklar1 $0.96 \AA$ ve N-H bağ uzunlukları $0.86 \AA$ olarak sabitlenmiştir. Hidrojen atomları eklendikten sonra izotropik arıtım işlemine tabi tutulmuştur. Yapı ağırlık fonksiyonu beklenen değerine eşitlenene kadar arıtım işlemine devam edilmiştir. Arıtımda SHELXL 97 (Sheldrick, 1997) yazılımı kullanılmıştır. Kristaline ait kristal parametreleri, veri toplama ve arıtım bilgileri Çizelge 1'de verilmiştir.

Çizelge 1. $\left[\mathrm{C}_{20} \mathrm{H}_{20} \mathrm{~N}_{4} \mathrm{~S}\right]$ Kristaline ait kristal parametreleri, veri toplama ve arıtım bilgileri

\begin{tabular}{|c|c|}
\hline Kristal Parametreleri & \\
\hline Kimyasal Formül & $\mathrm{C}_{20} \mathrm{H}_{20} \mathrm{~N}_{4} \mathrm{~S}$ \\
\hline Formül Ağılrlı̆̆ı (a.k.b.) & 348.460 \\
\hline Sicaklık (K) & 296 \\
\hline Kristal Sistemi & Ortorombik \\
\hline Uzay Grubu & P 212121 \\
\hline \multicolumn{2}{|l|}{ Birim Hücre Parametreleri } \\
\hline a b c $(\AA)$ & $6.208(5), 15.938(5), 19.573(5)$ \\
\hline$\alpha=\gamma=\beta\left(^{\circ}\right)$ & 90.00 \\
\hline Kristal Boyutları (mm) & $0.25 \times 0.27 \times 0.31$ \\
\hline Hacim, V $\left(\AA^{3}\right)$ & $1936.6(17)$ \\
\hline $\mathrm{Z}$ & 4 \\
\hline Soğurma Katsayısı, $\mu\left(\mathrm{mm}^{-1}\right)$ & 0.18 \\
\hline $\mathrm{F}_{000}$ & 736 \\
\hline Hesaplanan Yoğunluk $\left(\mathrm{Mg} / \mathrm{m}^{3}\right)$ & 1.195 \\
\hline \multicolumn{2}{|l|}{ Veri Toplama } \\
\hline Veri Toplanan Cihaz & Bruker APEX-II CCD \\
\hline Veri Toplama $\theta$ Aralığ $\left(^{\circ}\right)$ & $3.3 \leq \theta \leq 28.3$ \\
\hline \multicolumn{2}{|l|}{ İndeks Aralığg } \\
\hline $\mathrm{h}_{\min }, \mathrm{h}_{\max }$ & $-8,8$ \\
\hline $\mathrm{k}_{\min }, \mathrm{k}_{\max }$ & $-21,18$ \\
\hline $1_{\text {min }}, 1_{\max }$ & $-26,26$ \\
\hline Kırınım Toplama Yöntemi & If and Iw scans \\
\hline Ölçülen Yansıma & 29799 \\
\hline Bağımsız Yansıma & 4646 \\
\hline Gözlenen Yansıma [I > 2 $\sigma(\mathrm{I})]$ & 3693 \\
\hline Soğurma Düzeltmesi & multi-scan \\
\hline $\mathrm{T}_{\min }, \mathrm{T}_{\max }$ & $0.6456,0.7404$ \\
\hline $\mathrm{R}_{\text {int }}$ & 0.046 \\
\hline \multicolumn{2}{|l|}{ Verilerin Arıtılması } \\
\hline Yansıma Sayısı & 3693 \\
\hline Parametre Sayısı & 228 \\
\hline$R\left[F^{2}>2 \sigma\left(F^{2}\right)\right]$ & 0.063 \\
\hline$w R\left(F^{2}\right)$ & 0.125 \\
\hline GooF $=S$ & 1.13 \\
\hline$\Delta \varrho_{\min }, \Delta \varrho_{\max }\left(\mathrm{e} / \AA^{3}\right)$ & $-0.22,0.21$ \\
\hline
\end{tabular}


Kristalin tam çözümü gerçekleştirildikten sonra, Cambridge Kristalografik Data Merkezi'nin(Cambridge Crystallographic Data Centre (CCDC)) veri tabanı kullanılarak kristallerin ilk defa laboratuvarlarımızda sentezlendiği doğrulanmıştır. Moleküler çizimler için ORTEP-3 (Farrugia, 2012) programı, molekül-içi ve moleküller arası etkileşmelerin tespiti için ise PLATON (Spek, 2009) ve PARST (Nardelli, 1995) programları kullanılmıştır.

\section{Yüzey Analizi}

Bileşiğin kristal örgüsündeki moleküllerin paketlenmesinin doğasını anlamak ve moleküller arasındaki önemli etkileşimleri belirleyebilmek için Crystal Explorer 3.1 (Turner et al., 2017) programı kullanılarak Hirshfeld yüzey analizi gerçekleştirilmiştir. Programa giriş dosyası olarak $X$ - 1şını yapı çözümü sonucunda elde edilen kristale ait *.cif dosyası kullanılmıştır. Bileşik için normalize temas mesafeli $\left(\mathrm{d}_{\text {norm }}\right)$ Hirshfeld yüzeyi, Hirshfeld parmak izi haritası ve Hirshfeld yüzeyine katkıda bulunan etkileşimler ortaya çıkarılmıştır.

\section{BULGULAR VE TARTIŞMA}

\section{Kristalografik ve Moleküler Yapı}

Kristal monoklinik yapıda olup uzay grubu $\mathrm{P}$ 212121'dir ve birim hücrede molekül sayısı (Z) dörttür. Kristaldeki tüm atomlara ait kesirsel koordinatlar Çizelge 2.'de verilmiştir.

Kristalde fenil, siklobütan, tiyazol ve piridin halkalarının yanısıra Schiff baz'1 fonksiyonel grubu vardır. Fenil halkası C8 atomuyla siklobütan halkasına, siklobütan halkası $\mathrm{C} 12$ atomuyla tiyazol halkasına ve tiyazol halkası da Sciff bazı vasitasıyla piridin'e bağlanmıștır. Fenil ve tiyazol halkaları siklobütan halkasına göre cis konumundadır. Kristalinin moleküler yapısını gösteren çizim Şekil 1.'de, yapısal parametreler (bağ uzunlukları, bağ açıları ve torsiyon açıları) Çizelge 3.'de verilmiştir.

Fenil A (C1-C6), siklobütan B (C8-C11), tiyazol C (C12-C14/S1, N1) ve pyridine D (C16-C20/N4) olmak üzere, bu halkaların oluşturduğu düzlemler arasındaki dihedral açılar sırasıyla $83.64^{\circ}(\mathrm{A} / \mathrm{B}), 76.02^{\circ}(\mathrm{B} / \mathrm{C})$, $14.87^{\circ}$ (C/D), $89.94^{\circ}$ (A/C), $75.57^{\circ}$ (A/D), 71.59 (B/D)'dir.
Siklobütan halkası kelebek konformasyonuna sahiptir. $\mathrm{Bu}$ konformasyonda karbon atomları arasındaki bağ uzunlukları ortalama $1.555 \AA$ ve her üç karbon atomu tarafından oluşturulan bă açıları ise $88^{\circ}$ 'dir (Solomons and Fryhle, 2000). $\left[\mathrm{C}_{20} \mathrm{H}_{20} \mathrm{~N}_{4} \mathrm{~S}\right]$ kristali için sırasıyla bu değerler ortalama $1.541 \AA$ 的 $88.56^{\circ}$ olarak elde edilmiştir. Aynı zamanda siklobütan halkası için düzlemsellikten sapma miktarı $0.1223 \AA$ olarak bulunmuştur. Tiyazol halkası 2 konumundan C14 atomu vasitasiyla Schiff bazına, 4 konumunda C12 atomuyla siklobütan halkasına bağlanmıştır. S1-C13 ve $\mathrm{S} 1-\mathrm{C} 14$ bağ uzunlukları 1.730(3) $\AA$ ve 1.723(3) $\AA$ 'dur. Yine $\mathrm{C} 13-\mathrm{S} 1-\mathrm{C} 14$ ve $\mathrm{C} 12-\mathrm{N} 1-\mathrm{C} 14$ bağ açıları da sırasıyla $87.77(15)^{\circ}$ ve $109.9(2)^{\circ}$ 'dur. Tiyazol halkası için düzlemsellikten sapma miktarı $0.0057 \AA$ olarak bulunmuştur. Schiff bazı ve Piridin için C-N bağ uzunlukları sirasıyla literatürde 1.283 (7) $\AA$ (Şen ve ark., 2017) ve 1.319 (3) $\AA$ (Inkaya ve ark., 2013) olarak verilmiştir, $\left[\mathrm{C}_{20} \mathrm{H}_{20} \mathrm{~N}_{4} \mathrm{~S}\right]$ kristali için bu bağ uzunlukları (N3=C15) 1.277(4) $\AA$ ve (N3=C18) 1.333 (4) $\AA$ olarak elde edilmiştir.

Kristal yapıda dikkate değer bir molekül-içi ve beş moleküller arası hidrojen bağları tespit edilmiştir (Çizelge 4). Molekülün siklobütan halkasının C10 atomu ile tiyazolun $\mathrm{N} 1$ atomu arasinda H10A vasitasiyla molekül-içi bir etkileşme oluşmuştur. Moleküler paketlenmede ise'de bulunan molekülün $\mathrm{C} 11$ atomu $(\mathrm{x}-1 / 2,-\mathrm{y}+1 / 2,-\mathrm{z}+1)$ 'de bulunan molekülün tiyazol $\mathrm{S} 1$ atomuna hidrojen-bağ vericisi olarak davranmıştır.'de bulunan molekülün $\mathrm{N} 2$ atomu $(2-\mathrm{x}, 1 / 2+\mathrm{y}, 1 / 2-\mathrm{z})^{\text {‘de }}$ bulunan molekülün piridin $\mathrm{N} 4$ atomuna hidrojen-bağ vericisi olarak davranmıştır. Yine benzer şekilde 'de bulunan molekülün $\mathrm{C} 19$ atomunun $(\mathrm{x}, \mathrm{y}, \mathrm{z})^{6}$ de bulunan molekülün tiyazol $\mathrm{N} 1$ atomuna hidrojen-bağ vericisi olarak davranmıştır. $\mathrm{Bu} \mathrm{N} 2-\mathrm{H} 2 \mathrm{~N} \cdots \mathrm{N} 4$ ve $\mathrm{C} 19-$ H19 ‥N1 etkileşimleri birlikte bir halkası oluşturmuştur (Şekil 2). Bu hidrojen bağlarının yanı sıra moleküller arası $\mathrm{C}-\mathrm{H} \cdots \pi$ etkileşimi de üç boyutta paketlenmeye yardımcı olmaktadır. Şekil 3'de piridin halkasının (Cg1) merkezi ile C10 atomuna bağlı H10A atomu arasında ve tiyazol halkasının $(\mathrm{Cg} 2)$ merkezi ile $\mathrm{C} 13$ atomuna bağlı $\mathrm{H} 13$ atomu arasında oluşan $\mathrm{C}-\mathrm{H} \cdots \pi$ tipi etkileşim görülmektedir. Tüm hidrojen bağlarına ait $\mathrm{D}-\mathrm{H}, \mathrm{H} \cdots \mathrm{A}, \mathrm{D} \cdots \mathrm{A}$ uzunlukları ve $\mathrm{D}-\mathrm{H} \cdots \mathrm{A}$ açısı Çizelge 4. 'de verilmiştir. Kristalde $\pi \cdots \pi$ etkileşimlerine rastlanmamıştır. 
Çizelge 2. $\left[\mathrm{C}_{20} \mathrm{H}_{20} \mathrm{~N}_{4} \mathrm{~S}\right]$ kristalindeki atomların kesirsel koordinatları ve Uiso* Ueq $\left(\AA^{2}\right)^{-1}$ değerleri

\begin{tabular}{|c|c|c|c|c|}
\hline Atom & $x$ & $y$ & $z$ & $U_{\text {iso }} * / U_{\text {eq }}$ \\
\hline $\mathrm{C} 1$ & $0.9303(6)$ & $-0.0975(2)$ & $0.55200(17)$ & $0.0608(8)$ \\
\hline $\mathrm{C} 2$ & $0.8507(10)$ & $-0.1380(2)$ & $0.6070(2)$ & $0.1132(18)$ \\
\hline $\mathrm{H} 2$ & 0.7203 & -0.1208 & 0.6257 & $0.136^{*}$ \\
\hline $\mathrm{C} 3$ & $0.9616(14)$ & $-0.2056(3)$ & $0.6362(3)$ & $0.155(3)$ \\
\hline $\mathrm{H} 3$ & 0.9043 & -0.2334 & 0.6738 & $0.186^{*}$ \\
\hline $\mathrm{C} 4$ & $1.1517(13)$ & $-0.2303(3)$ & $0.6095(3)$ & $0.131(2)$ \\
\hline $\mathrm{H} 4$ & 1.2295 & -0.2731 & 0.6303 & $0.158^{*}$ \\
\hline $\mathrm{C} 5$ & $1.2293(10)$ & $-0.1930(3)$ & $0.5527(4)$ & $0.127(2)$ \\
\hline $\mathrm{H} 5$ & 1.3547 & -0.2129 & 0.5324 & $0.153 *$ \\
\hline C6 & $1.1216(7)$ & $-0.1248(3)$ & $0.5245(3)$ & $0.0977(14)$ \\
\hline H6 & 1.1795 & -0.0974 & 0.4868 & $0.117 *$ \\
\hline $\mathrm{C} 7$ & $0.6809(8)$ & $-0.0558(2)$ & $0.45825(19)$ & $0.0864(13)$ \\
\hline H7A & 0.5787 & -0.0972 & 0.4729 & $0.130 *$ \\
\hline H7B & 0.7765 & -0.0800 & 0.4251 & $0.130^{*}$ \\
\hline $\mathrm{H} 7 \mathrm{C}$ & 0.6060 & -0.0092 & 0.4381 & $0.130 *$ \\
\hline $\mathrm{C} 8$ & $0.8120(5)$ & $-0.02501(17)$ & $0.52019(15)$ & $0.0528(7)$ \\
\hline $\mathrm{C} 9$ & $0.9431(6)$ & $0.05409(18)$ & $0.50076(17)$ & $0.0612(9)$ \\
\hline H9A & 1.0776 & 0.0596 & 0.5256 & $0.073^{*}$ \\
\hline H9B & 0.9659 & 0.0604 & 0.4520 & $0.073^{*}$ \\
\hline $\mathrm{C} 10$ & $0.6783(5)$ & $0.03187(17)$ & $0.56796(17)$ & $0.0584(8)$ \\
\hline H10B & 0.5240 & 0.0233 & 0.5642 & $0.070^{*}$ \\
\hline H10A & 0.7242 & 0.0300 & 0.6153 & $0.070 *$ \\
\hline $\mathrm{C} 11$ & $0.7597(6)$ & $0.10910(18)$ & $0.52916(16)$ & $0.0585(8)$ \\
\hline H11 & 0.6588 & 0.1231 & 0.4924 & $0.070 *$ \\
\hline $\mathrm{C} 12$ & $0.8189(5)$ & $0.18679(16)$ & $0.56729(14)$ & $0.0489(7)$ \\
\hline $\mathrm{C} 13$ & $0.7154(6)$ & $0.26071(19)$ & $0.56384(17)$ & $0.0634(9)$ \\
\hline $\mathrm{H} 13$ & 0.5914 & 0.2703 & 0.5383 & $0.076^{*}$ \\
\hline $\mathrm{C} 14$ & $1.0283(5)$ & 0.25967 (16) & $0.63526(14)$ & $0.0463(7)$ \\
\hline $\mathrm{C} 15$ & $1.4073(5)$ & $0.37528(18)$ & $0.72611(15)$ & $0.0516(7)$ \\
\hline H15 & 1.4986 & 0.3319 & 0.7392 & $0.062 *$ \\
\hline $\mathrm{C} 16$ & $1.4602(5)$ & $0.46239(18)$ & 0.74414 (14) & $0.0506(7)$ \\
\hline $\mathrm{C} 17$ & $1.3193(6)$ & $0.52834(18)$ & $0.73289(14)$ & $0.0573(8)$ \\
\hline $\mathrm{H} 17$ & 1.1859 & 0.5189 & 0.7127 & $0.069 *$ \\
\hline $\mathrm{C} 18$ & $1.3797(6)$ & $0.6086(2)$ & $0.75208(17)$ & $0.0667(9)$ \\
\hline H18 & 1.2825 & 0.6521 & 0.7450 & $0.080^{*}$ \\
\hline C19 & $1.7019(6)$ & $0.5628(2)$ & $0.7912(2)$ & $0.0749(10)$ \\
\hline H19 & 1.8345 & 0.5740 & 0.8113 & $0.090 *$ \\
\hline $\mathrm{C} 20$ & $1.6547(6)$ & $0.4804(2)$ & $0.77457(18)$ & $0.0650(9)$ \\
\hline $\mathrm{H} 20$ & 1.7529 & 0.4378 & 0.7838 & $0.078^{*}$ \\
\hline $\mathrm{N} 1$ & $0.9970(4)$ & $0.18558(13)$ & $0.60912(12)$ & $0.0501(6)$ \\
\hline $\mathrm{N} 2$ & $1.1973(5)$ & $0.27758(14)$ & $0.67656(13)$ & $0.0600(7)$ \\
\hline $\mathrm{H} 2 \mathrm{~N}$ & 1.2781 & 0.2383 & 0.6924 & $0.072 *$ \\
\hline $\mathrm{N} 3$ & $1.2361(4)$ & $0.35917(14)$ & $0.69242(12)$ & $0.0515(6)$ \\
\hline $\mathrm{N} 4$ & $1.5696(5)$ & $0.62674(17)$ & $0.78015(16)$ & $0.0706(8)$ \\
\hline S1 & $0.84354(14)$ & $0.33564(5)$ & $0.61316(5)$ & $0.0614(2)$ \\
\hline
\end{tabular}


Çizelge 3. $\left[\mathrm{C}_{20} \mathrm{H}_{20} \mathrm{~N}_{4} \mathrm{~S}\right]$ kristaline ait yapısal parametreler

\begin{tabular}{|c|c|c|c|c|c|}
\hline $\begin{array}{c}\text { Bağ } \\
\text { uzunlukları }\end{array}$ & $\AA$ & Bağ açıları & $\left({ }^{\circ}\right)$ & Torsiyon açıları & $\left({ }^{\circ}\right)$ \\
\hline $\mathrm{C} 1-\mathrm{C} 2$ & $1.348(5)$ & $\mathrm{C} 2-\mathrm{C} 1-\mathrm{C} 6$ & $118.5(4)$ & $\mathrm{C} 6-\mathrm{C} 1-\mathrm{C} 2-\mathrm{C} 3$ & $0.9(7)$ \\
\hline $\mathrm{C} 1-\mathrm{C} 6$ & $1.374(5)$ & $\mathrm{C} 2-\mathrm{C} 1-\mathrm{C} 9$ & $121.3(4)$ & $\mathrm{C} 9-\mathrm{C} 1-\mathrm{C} 2-\mathrm{C} 3$ & $179.8(4)$ \\
\hline $\mathrm{C} 1-\mathrm{C} 9$ & $1.504(5)$ & $\mathrm{C} 6-\mathrm{C} 1-\mathrm{C} 9$ & $120.2(4)$ & $\mathrm{C} 1-\mathrm{C} 2-\mathrm{C} 3-\mathrm{C} 4$ & $0.6(9)$ \\
\hline $\mathrm{C} 2-\mathrm{C} 3$ & $1.400(6)$ & $\mathrm{C} 1-\mathrm{C} 2-\mathrm{C} 3$ & $120.9(5)$ & $\mathrm{C} 2-\mathrm{C} 3-\mathrm{C} 4-\mathrm{C} 5$ & $-3.6(10)$ \\
\hline $\mathrm{C} 3-\mathrm{C} 4$ & $1.349(9)$ & $\mathrm{C} 4-\mathrm{C} 3-\mathrm{C} 2$ & $119.8(5)$ & $\mathrm{C} 3-\mathrm{C} 4-\mathrm{C} 5-\mathrm{C} 6$ & $5.0(9)$ \\
\hline $\mathrm{C} 4-\mathrm{C} 5$ & $1.350(8)$ & $\mathrm{C} 3-\mathrm{C} 4-\mathrm{C} 5$ & $120.2(5)$ & $\mathrm{C} 2-\mathrm{C} 1-\mathrm{C} 6-\mathrm{C} 5$ & $0.4(6)$ \\
\hline $\mathrm{C} 5-\mathrm{C} 6$ & $1.390(6)$ & $\mathrm{C} 4-\mathrm{C} 5-\mathrm{C} 6$ & $119.9(6)$ & $\mathrm{C} 9-\mathrm{C} 1-\mathrm{C} 6-\mathrm{C} 5$ & $-178.5(4)$ \\
\hline $\mathrm{C} 8-\mathrm{C} 9$ & $1.540(4)$ & $\mathrm{C} 1-\mathrm{C} 6-\mathrm{C} 5$ & $120.5(5)$ & $\mathrm{C} 4-\mathrm{C} 5-\mathrm{C} 6-\mathrm{C} 1$ & $-3.4(8)$ \\
\hline $\mathrm{C} 9-\mathrm{C} 11$ & $1.544(4)$ & $\mathrm{C} 13-\mathrm{C} 12-\mathrm{C} 11$ & $120.0(3)$ & $\mathrm{C} 2-\mathrm{C} 1-\mathrm{C} 9-\mathrm{C} 8$ & $-97.6(4)$ \\
\hline $\mathrm{C} 9-\mathrm{C} 10$ & $1.548(4)$ & $\mathrm{C} 13-\mathrm{C} 12-\mathrm{C} 10$ & $118.1(3)$ & $\mathrm{C} 6-\mathrm{C} 1-\mathrm{C} 9-\mathrm{C} 8$ & $81.3(4)$ \\
\hline $\mathrm{C} 12-\mathrm{C} 13$ & $1.492(4)$ & $\mathrm{C} 11-\mathrm{C} 12-\mathrm{C} 10$ & $88.0(2)$ & $\mathrm{C} 2-\mathrm{C} 1-\mathrm{C} 9-\mathrm{C} 11$ & $32.5(5)$ \\
\hline $\mathrm{C} 13-\mathrm{C} 14$ & $1.344(4)$ & $\mathrm{C} 14-\mathrm{C} 13-\mathrm{N} 1$ & $115.2(3)$ & $\mathrm{C} 6-\mathrm{C} 1-\mathrm{C} 9-\mathrm{C} 11$ & $-148.6(3)$ \\
\hline $\mathrm{C} 13-\mathrm{N} 1$ & $1.376(4)$ & $\mathrm{C} 14-\mathrm{C} 13-\mathrm{C} 12$ & $125.8(3)$ & $\mathrm{C} 2-\mathrm{C} 1-\mathrm{C} 9-\mathrm{C} 10$ & $135.1(4)$ \\
\hline $\mathrm{C} 14-\mathrm{S} 1$ & $1.730(3)$ & $\mathrm{N} 1-\mathrm{C} 13-\mathrm{C} 12$ & $119.0(2)$ & $\mathrm{C} 6-\mathrm{C} 1-\mathrm{C} 9-\mathrm{C} 10$ & $-46.0(4)$ \\
\hline $\mathrm{C} 15-\mathrm{N} 1$ & $1.302(3)$ & $\mathrm{C} 13-\mathrm{C} 14-\mathrm{S} 1$ & $110.9(2)$ & $\mathrm{C} 1-\mathrm{C} 9-\mathrm{C} 10-\mathrm{C} 12$ & $-137.9(3)$ \\
\hline $\mathrm{C} 15-\mathrm{N} 2$ & $1.355(4)$ & $\mathrm{N} 1-\mathrm{C} 15-\mathrm{N} 2$ & $122.8(3)$ & $\mathrm{C} 8-\mathrm{C} 9-\mathrm{C} 10-\mathrm{C} 12$ & $94.9(3)$ \\
\hline $\mathrm{C} 15-\mathrm{S} 1$ & $1.723(3)$ & $\mathrm{N} 1-\mathrm{C} 15-\mathrm{S} 1$ & $116.1(2)$ & $\mathrm{C} 11-\mathrm{C} 9-\mathrm{C} 10-\mathrm{C} 12$ & $-17.9(2)$ \\
\hline $\mathrm{C} 16-\mathrm{N} 3$ & $1.277(4)$ & $\mathrm{N} 2-\mathrm{C} 15-\mathrm{S} 1$ & $121.2(2)$ & $\mathrm{C} 1-\mathrm{C} 9-\mathrm{C} 11-\mathrm{C} 12$ & $138.5(3)$ \\
\hline $\mathrm{C} 16-\mathrm{C} 17$ & $1.470(4)$ & $\mathrm{N} 3-\mathrm{C} 16-\mathrm{C} 17$ & $120.0(3)$ & $\mathrm{C} 8-\mathrm{C} 9-\mathrm{C} 11-\mathrm{C} 12$ & $-92.6(3)$ \\
\hline $\mathrm{C} 17-\mathrm{C} 21$ & $1.377(5)$ & $\mathrm{C} 21-\mathrm{C} 17-\mathrm{C} 18$ & $117.7(3)$ & $\mathrm{C} 10-\mathrm{C} 9-\mathrm{C} 11-\mathrm{C} 12$ & $18.0(2)$ \\
\hline $\mathrm{C} 17-\mathrm{C} 18$ & $1.385(4)$ & $\mathrm{C} 21-\mathrm{C} 17-\mathrm{C} 16$ & $119.8(3)$ & $\mathrm{C} 9-\mathrm{C} 11-\mathrm{C} 12-\mathrm{C} 13$ & $-139.7(3)$ \\
\hline $\mathrm{C} 18-\mathrm{C} 19$ & $1.385(4)$ & $\mathrm{C} 18-\mathrm{C} 17-\mathrm{C} 16$ & $122.6(3)$ & $\mathrm{C} 9-\mathrm{C} 11-\mathrm{C} 12-\mathrm{C} 10$ & $-18.1(2)$ \\
\hline $\mathrm{C} 19-\mathrm{N} 4$ & $1.333(4)$ & $\mathrm{C} 19-\mathrm{C} 18-\mathrm{C} 17$ & $119.2(3)$ & $\mathrm{C} 9-\mathrm{C} 10-\mathrm{C} 12-\mathrm{C} 13$ & $141.4(3)$ \\
\hline $\mathrm{C} 10-\mathrm{C} 12$ & $1.541(4)$ & $\mathrm{C} 1-\mathrm{C} 9-\mathrm{C} 8$ & $109.8(3)$ & $\mathrm{C} 9-\mathrm{C} 10-\mathrm{C} 12-\mathrm{C} 11$ & $18.1(2)$ \\
\hline $\mathrm{C} 11-\mathrm{C} 12$ & $1.532(4)$ & $\mathrm{C} 1-\mathrm{C} 9-\mathrm{C} 11$ & $117.6(3)$ & $\mathrm{C} 11-\mathrm{C} 12-\mathrm{C} 13-\mathrm{C} 14$ & $-113.4(4)$ \\
\hline $\mathrm{C} 20-\mathrm{N} 4$ & $1.327(5)$ & $\mathrm{C} 8-\mathrm{C} 9-\mathrm{C} 11$ & $112.3(3)$ & $\mathrm{C} 10-\mathrm{C} 12-\mathrm{C} 13-\mathrm{C} 14$ & $141.4(3)$ \\
\hline $\mathrm{C} 20-\mathrm{C} 21$ & $1.384(4)$ & $\mathrm{C} 1-\mathrm{C} 9-\mathrm{C} 10$ & $118.1(3)$ & $\mathrm{C} 11-\mathrm{C} 12-\mathrm{C} 13-\mathrm{N} 1$ & $68.0(4)$ \\
\hline \multirow[t]{24}{*}{$\mathrm{N} 2-\mathrm{N} 3$} & $1.358(3)$ & $\mathrm{C} 8-\mathrm{C} 9-\mathrm{C} 10$ & $110.1(3)$ & $\mathrm{C} 10-\mathrm{C} 12-\mathrm{C} 13-\mathrm{N} 1$ & $-37.2(4)$ \\
\hline & & $\mathrm{C} 11-\mathrm{C} 9-\mathrm{C} 10$ & $87.3(2)$ & $\mathrm{N} 1-\mathrm{C} 13-\mathrm{C} 14-\mathrm{S} 1$ & $1.3(4)$ \\
\hline & & $\mathrm{C} 12-\mathrm{C} 10-\mathrm{C} 9$ & $89.2(2)$ & $\mathrm{C} 12-\mathrm{C} 13-\mathrm{C} 14-\mathrm{S} 1$ & $-177.3(2)$ \\
\hline & & $\mathrm{N} 4-\mathrm{C} 19-\mathrm{C} 18$ & $123.5(3)$ & $\mathrm{N} 3-\mathrm{C} 16-\mathrm{C} 17-\mathrm{C} 21$ & $-173.7(3)$ \\
\hline & & $\mathrm{N} 4-\mathrm{C} 20-\mathrm{C} 21$ & $124.1(4)$ & $\mathrm{N} 3-\mathrm{C} 16-\mathrm{C} 17-\mathrm{C} 18$ & $7.5(4)$ \\
\hline & & $\mathrm{C} 17-\mathrm{C} 21-\mathrm{C} 20$ & $119.0(3)$ & $\mathrm{C} 21-\mathrm{C} 17-\mathrm{C} 18-\mathrm{C} 19$ & $0.4(5)$ \\
\hline & & $\mathrm{C} 12-\mathrm{C} 11-\mathrm{C} 9$ & $89.7(2)$ & $\mathrm{C} 16-\mathrm{C} 17-\mathrm{C} 18-\mathrm{C} 19$ & $179.2(3)$ \\
\hline & & $\mathrm{C} 15-\mathrm{N} 1-\mathrm{C} 13$ & $109.9(2)$ & $\mathrm{C} 17-\mathrm{C} 18-\mathrm{C} 19-\mathrm{N} 4$ & $1.2(5)$ \\
\hline & & $\mathrm{C} 15-\mathrm{N} 2-\mathrm{N} 3$ & $118.4(2)$ & $\mathrm{C} 18-\mathrm{C} 17-\mathrm{C} 21-\mathrm{C} 20$ & $-1.2(5)$ \\
\hline & & $\mathrm{C} 16-\mathrm{N} 3-\mathrm{N} 2$ & $117.3(3)$ & $\mathrm{C} 16-\mathrm{C} 17-\mathrm{C} 21-\mathrm{C} 20$ & $180.0(3)$ \\
\hline & & $\mathrm{C} 20-\mathrm{N} 4-\mathrm{C} 19$ & $116.6(3)$ & $\mathrm{N} 4-\mathrm{C} 20-\mathrm{C} 21-\mathrm{C} 17$ & $0.6(6)$ \\
\hline & & $\mathrm{C} 15-\mathrm{S} 1-\mathrm{C} 14$ & $87.77(15)$ & $\mathrm{N} 2-\mathrm{C} 15-\mathrm{N} 1-\mathrm{C} 13$ & $-177.5(3)$ \\
\hline & & & & $\mathrm{S} 1-\mathrm{C} 15-\mathrm{N} 1-\mathrm{C} 13$ & $1.4(3)$ \\
\hline & & & & $\mathrm{C} 14-\mathrm{C} 13-\mathrm{N} 1-\mathrm{C} 15$ & $-1.7(4)$ \\
\hline & & & & $\mathrm{C} 12-\mathrm{C} 13-\mathrm{N} 1-\mathrm{C} 15$ & $177.0(3)$ \\
\hline & & & & $\mathrm{N} 1-\mathrm{C} 15-\mathrm{N} 2-\mathrm{N} 3$ & $169.6(3)$ \\
\hline & & & & $\mathrm{S} 1-\mathrm{C} 15-\mathrm{N} 2-\mathrm{N} 3$ & $-9.3(4)$ \\
\hline & & & & $\mathrm{C} 17-\mathrm{C} 16-\mathrm{N} 3-\mathrm{N} 2$ & $179.2(3)$ \\
\hline & & & & $\mathrm{C} 15-\mathrm{N} 2-\mathrm{N} 3-\mathrm{C} 16$ & $-173.7(3)$ \\
\hline & & & & $\mathrm{C} 21-\mathrm{C} 20-\mathrm{N} 4-\mathrm{C} 19$ & $0.8(6)$ \\
\hline & & & & $\mathrm{C} 18-\mathrm{C} 19-\mathrm{N} 4-\mathrm{C} 20$ & $-1.7(5)$ \\
\hline & & & & $\mathrm{N} 1-\mathrm{C} 15-\mathrm{S} 1-\mathrm{C} 14$ & $-0.6(3)$ \\
\hline & & & & $\mathrm{N} 2-\mathrm{C} 15-\mathrm{S} 1-\mathrm{C} 14$ & $178.3(3)$ \\
\hline & & & & $\mathrm{C} 13-\mathrm{C} 14-\mathrm{S} 1-\mathrm{C} 15$ & $-0.4(3)$ \\
\hline
\end{tabular}




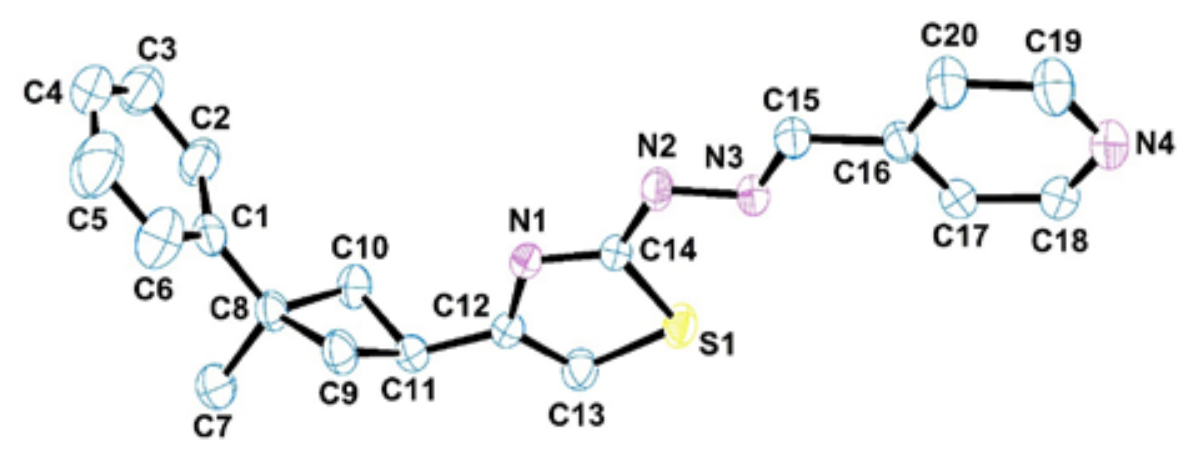

Şekil 1. $\left[\mathrm{C}_{20} \mathrm{H}_{20} \mathrm{~N}_{4} \mathrm{~S}\right]$ kristaline ait \%30 olasılıklı 1sısal elipsoitlerle çizilmiş ORTEP - 3 diyagramı. Açık bir görünüm için hidrojen atomları silinmiştir.

Çizelge 4. $\left[\mathrm{C}_{20} \mathrm{H}_{20} \mathrm{~N}_{4} \mathrm{~S}\right]$ kristaline ait hidrojen bağ 1 geometrisi $(\AA \stackrel{\circ}{\circ})$

\begin{tabular}{|l|c|c|c|c|}
\hline $\mathbf{D}-\mathbf{H} \cdots \mathbf{A}$ & $\mathbf{D}-\mathbf{H}$ & $\mathbf{H} \cdots \mathbf{A}$ & $\mathbf{D} \cdots \mathbf{A}$ & $\mathbf{D}-\mathbf{H} \cdots \mathbf{A}$ \\
\hline $\mathrm{C} 9-\mathrm{H} 9 \mathrm{~A} \cdots \mathrm{N} 1$ & 0.97 & 2.615 & $3.000(4)$ & 100 \\
\hline $\mathrm{C} 11-\mathrm{H} 11 \cdots \mathrm{S} 1^{\mathrm{i}}$ & 0.98 & 2.821 & $3.900(4)$ & 178 \\
\hline $\mathrm{N} 2-\mathrm{H} 2 \mathrm{~N} \cdots \mathrm{N} 4{ }^{\mathrm{ii}}$ & 0.86 & 2.08 & $2.931(4)$ & 168 \\
\hline $\mathrm{C} 19-\mathrm{H} 19 \cdots \mathrm{N} 1^{\mathrm{iii}}$ & 0.93 & 2.59 & $3.336(5)$ & 138 \\
\hline $\mathrm{C} 10-\mathrm{H} 10 \mathrm{~A} \cdots \mathrm{Cg} 1^{\text {iv }}$ & 0.97 & 2.82 & $3.533(5)$ & 131 \\
\hline $\mathrm{C} 13-\mathrm{H} 13 \cdots \mathrm{Cg} 2^{\mathrm{v}}$ & 0.93 & 2.98 & $3.785(5)$ & 146 \\
\hline
\end{tabular}

Simetri kodları: (i) $\mathrm{x}-1 / 2,-\mathrm{y}+1 / 2,-\mathrm{z}+1$; (ii) $2-\mathrm{x}, 1 / 2+\mathrm{y}, 1 / 2-\mathrm{z}$; (iii) $2-\mathrm{x},-1 / 2+\mathrm{y}, 1 / 2-\mathrm{z}$; (iv) $1-\mathrm{x}, 1 / 2+\mathrm{y}, 1 / 2-\mathrm{z}$; (v) -1/2+x,1/2-y,1-z. Cg1 piridin Cg2 tiyazol halkasının merkezidir.

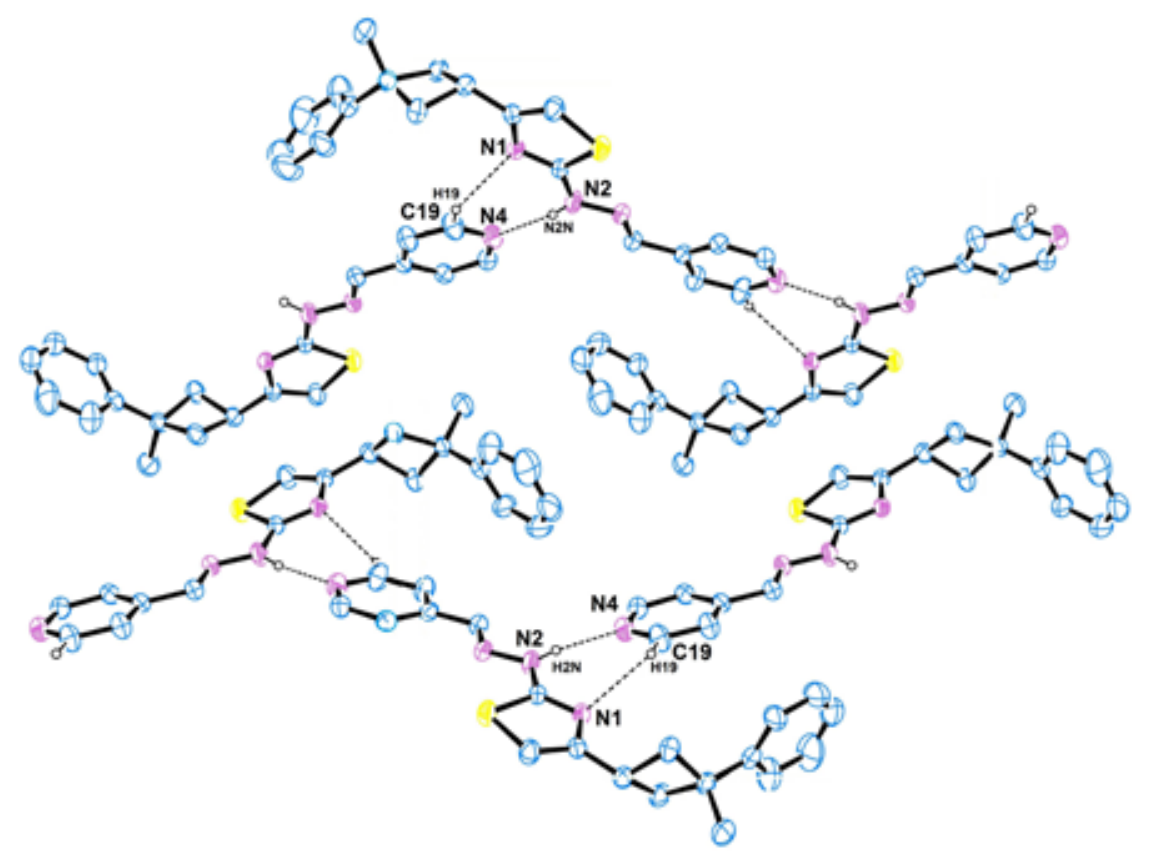

Şekil 2. $\left[\mathrm{C}_{20} \mathrm{H}_{20} \mathrm{~N}_{4} \mathrm{~S}\right]$ kristalinin [100] doğrultusu boyunca $\mathrm{N} 2-\mathrm{H} 2 \mathrm{~N} \cdots \mathrm{N} 4$ ve C19-H19 $\cdots \mathrm{N} 1$ etkileşimlerinin oluşturduğu $\mathrm{R}_{2}^{2}(7)$ zincir motifini gösteren kristal yapısının bir bölümü. Açık bir görünüm için bağlanmaya katılmayan hidrojenler gösterilmemiştir. 


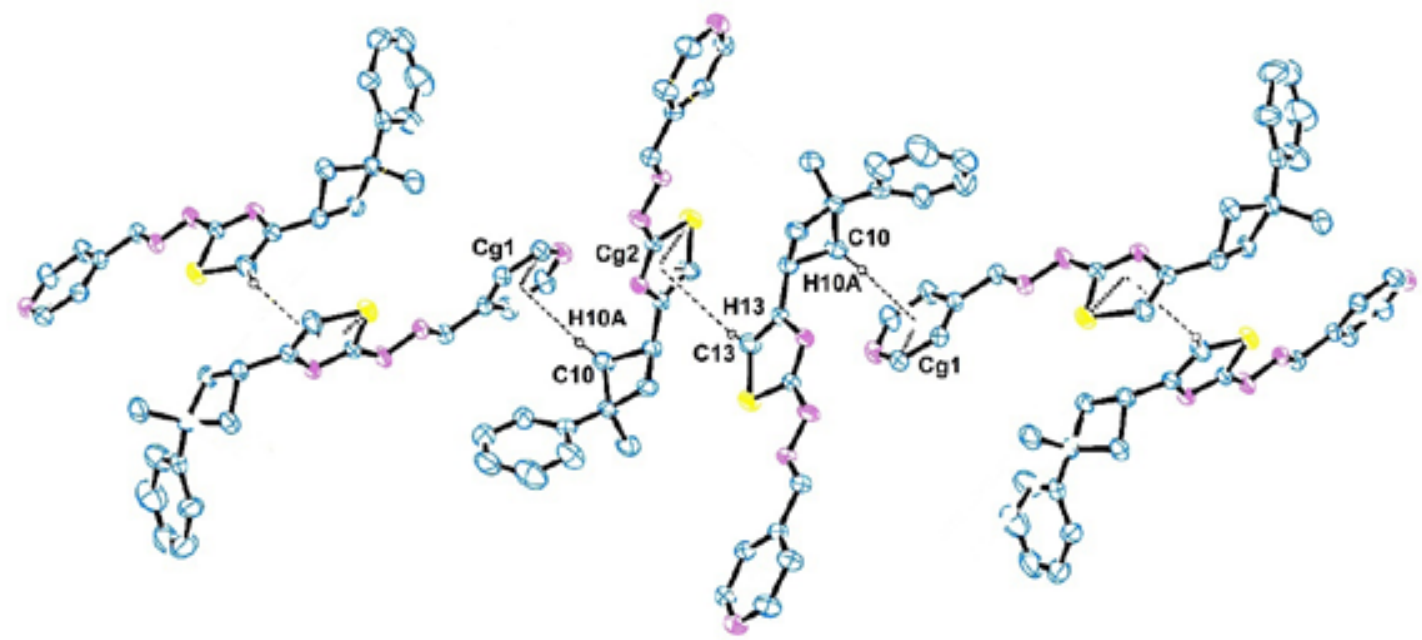

Şekil 3. $\left[\mathrm{C}_{20} \mathrm{H}_{20} \mathrm{~N}_{4} \mathrm{~S}\right]$ kristalinin $\mathrm{C} 10-\mathrm{H} 10 \mathrm{~A} \cdots \mathrm{Cg} 1$ ve $\mathrm{C} 13-\mathrm{H} 13 \cdots \mathrm{Cg} 2$ etkileşimlerini gösteren kristal yapısının bir bölümü. Açık bir görünüm için bağlanmaya katılmayan hidrojenler gösterilmemiştir.

\section{Hirshfeld Yüzeyi}

Bir molekülün Hirshfeld yüzeyinin elde edilmesinde iki parametre tanımlanır: Bunlar;

$\mathrm{d}_{\mathrm{e}}:$ Hirshfeld yüzeyinden yüzeyin dışındaki en yakın çekirdeğe olan uzaklık gelen uzaklıktır.

$\mathrm{d}_{\mathrm{i}}$ :Yüzeyin içindeki en yakın çekirdeğe karşılık

Normalize temas mesafesi $\left(d_{\text {norm }}\right) d_{e}, d_{i}$ ve atomun van der waals $(\mathrm{vdw})$ yarıçapına bağglıdır. $d_{\text {norm }}$;

ile formülize edilir. $\mathrm{Bu}$ eşitlik moleküller-arası hidrojen bağları için özel önem taşıyan bölgelerin belirlenmesini sağlar. $d_{\text {norm }}$ kırmızı, beyaz ve mavi renkten oluşur. Eğer atomlar van der waals (vdw) yarıçaplarının toplamından daha yakın moleküller arası bă̆ yapıyorlarsa, bu bağlar yüzey üzerinden kırmızı bir nokta ile verilir. Van der waals (vdw) yarıçaplarının toplamından uzak ise mavi, yakın ise beyaz renk ile gösterilir (Spackman and McKinnona, 2002; Spackman and Jayatilaka, 2009).

Bileşiğin Hirshfeld yüzey analizi Crystal Explorer 3.1 (Turner et al., 2017) programı vasitasiyla gerçekleştirilmiştir ve bileşik için $d_{\text {norm }}$ Hirshfeld yüzeyi (Şekil 4), şekil indeksi (Şekil 5a) ve eğrilik (Şekil 5b) oluşturulmuştur. Bu yüzeyler 3 boyutlu olarak $\mathrm{d}_{\text {norm }}-0.538$ (kırmızı) ile $1.981 \AA$ (mavi) renk skalasında, şekil indeksi $-1.000+1.000$ aralığında ve eğrilik $-4.000+4.000$ aralığında elde edilmiştir.

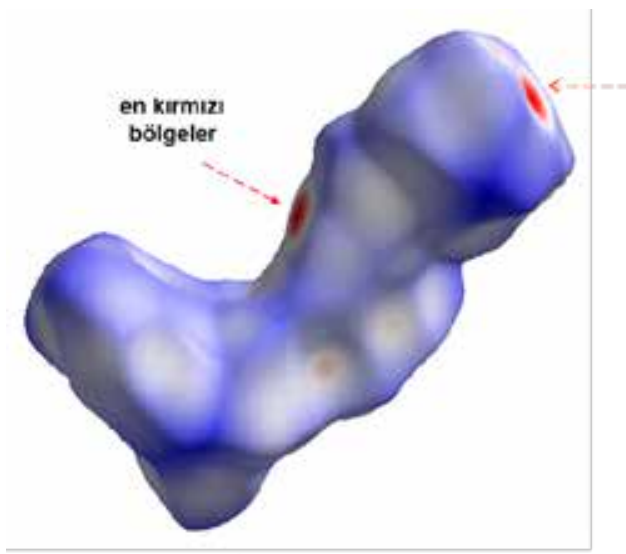

a)
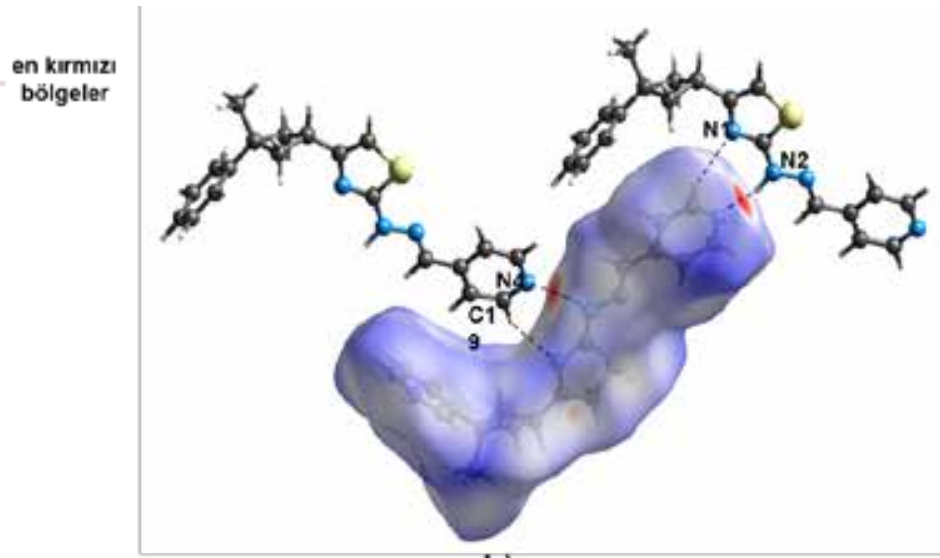

b)
Şekil 4. $\quad$ a) Hirshfeld yüzeyi $\left(\mathrm{d}_{\text {norm }}\right)$.

b) Kırmızı noktalar verici-alıcı etkileşim bölgelerini göstermektedir. 


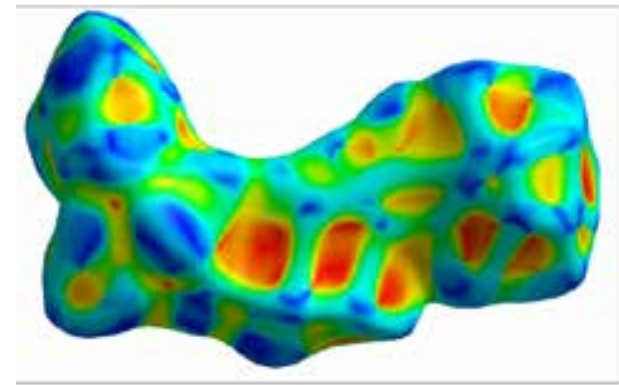

a)

Şekil 5. a) Şekil indeksi,

Hirshfeld yüzeyinde $\left(\mathrm{d}_{\text {norm }}\right)$ koyu kırmızı noktalar açık kırmızı noktalara göre daha kuvvetli hidojen bağlarını göstermektedir. Şekil 4a'da toplam 8 kırmızı bölge vardır. Bu bölgelerden 2'si diğerlerine nazaran daha koyu renkli ve büyüktür. Daha açık küçük kırmızı bölgeler S1, H11, H19, N1, H13 ve tiyazol halkasının merkezi üzerine yerleşmiştir ve Çizelge 4.'de verilen C9-H9A $\cdots \mathrm{N} 1, \quad \mathrm{C} 11-\mathrm{H} 11 \cdots \mathrm{S} 1, \quad \mathrm{C} 19-\mathrm{H} 19 \cdots \mathrm{N} 1$, $\mathrm{C} 13-\mathrm{H} 13 \cdots \mathrm{Cg} 2$ hidrojen bağlarını doğrulayacak şekildedir.

En koyu kırmızı 2 bölge ise $\mathrm{H} 2 \mathrm{~N}$ ve $\mathrm{N} 4$ atomunun üzerine yerleşmiştir ve bu bölgeler de Çizelge 4.'de

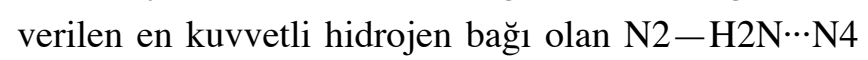
ve C19-H19..NN1 moleküller-arası hidrojen bağlarını doğrulayacak şekildedir. Hirshfeld yüzeyi ile PLATON ve PARST verileri uyum içindedir.

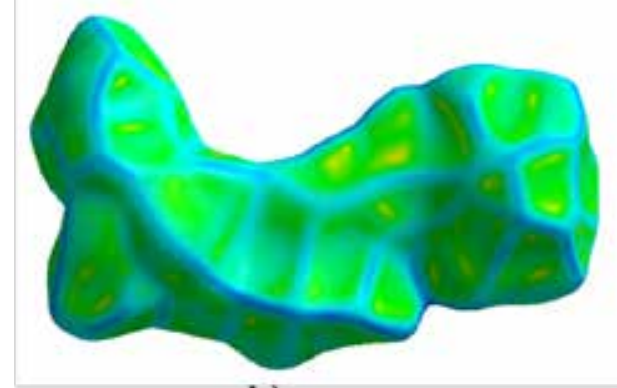

b)

b) Eğrilik

Hirshfeld yüzeyinin 2 boyutlu gösterimi 'parmak izi çizimi’ olarak adlandırılır ve bu çizim x ekseni $d_{i}$, y ekseni $d_{e}$ olmak üzere elde edilir. Mavi noktalardan oluşur ve adından da anlaşılacağı üzere parmak izine benzer. Bileşiğin parmak izi gösterimi Şekil 6.'da verilmiştir. $\mathrm{Bu}$ çizimde gösterilmiş olan keskin sivri uçlar S $\cdots \mathrm{H} / \mathrm{H} \cdots \mathrm{S}, \mathrm{C} \cdots \mathrm{H} / \mathrm{H} \cdots \mathrm{C}, \mathrm{N} \cdots \mathrm{H} / \mathrm{H} \cdots \mathrm{N}$ ve $\mathrm{H} \cdots \mathrm{H}$ / $\mathrm{H} \cdots \mathrm{H}$ etkileşimlerine aittir. $\mathrm{H} \cdots \mathrm{H} / \mathrm{H} \cdots \mathrm{H}$ etkileşimleri parmak izi çiziminin yüzde 48,8 'ünü oluşturur ki bu yüzde çizime katkıda bulunan en büyük yüzdedir

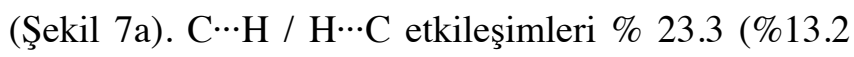
$+\% 10.2)($ Şekil $7 \mathrm{~b}), \mathrm{N} \cdots \mathrm{H} / \mathrm{H} \cdots \mathrm{N}$ etkileşimleri \%15.1 $(\% 8.3+\% 6.8)($ Şekil $7 \mathrm{c}), \mathrm{S} \cdots \mathrm{H} / \mathrm{H} \cdots \mathrm{S}$ etkileşimleri $\% 8.3(\% 4.7+\% 3.6)($ Şekil $7 \mathrm{~d})$ ile parmak izi çizimine katkıda bulunur. $\mathrm{H} \cdots \mathrm{H} / \mathrm{H} \cdots \mathrm{H}$ etkileşimleri dışında bu etkileşimler parmak izinde kuş kanatları şeklindedir.

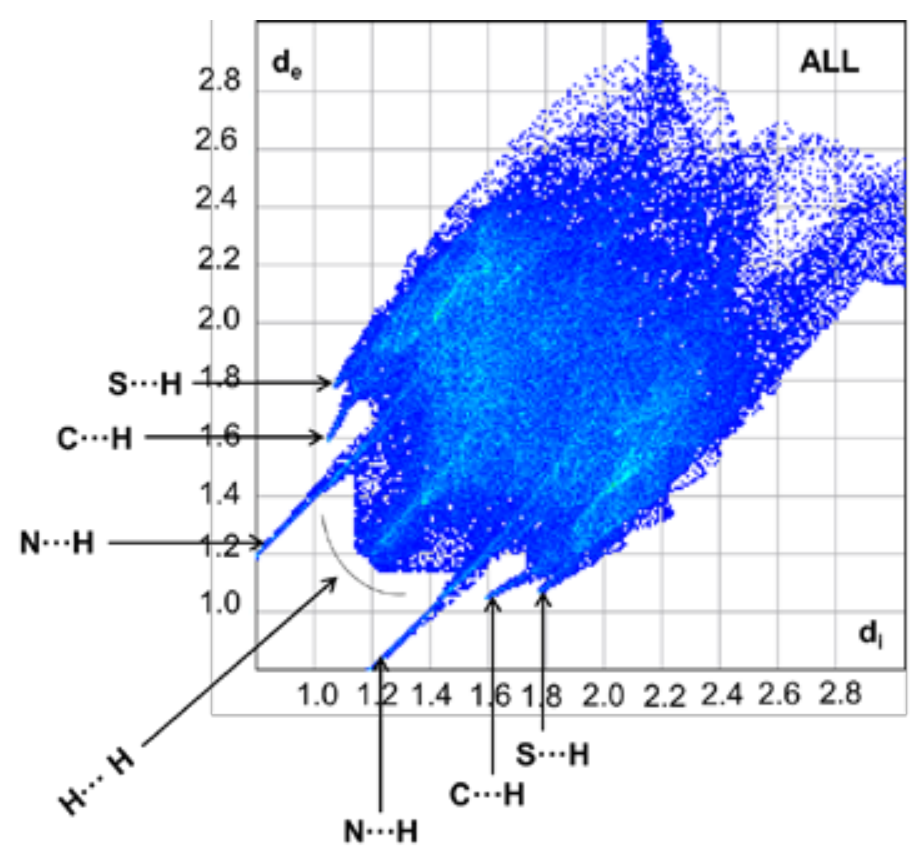

Şekil 6. Hirshfeld yüzeyinin 2 boyutlu gösterimi (parmak izi çizimi) 


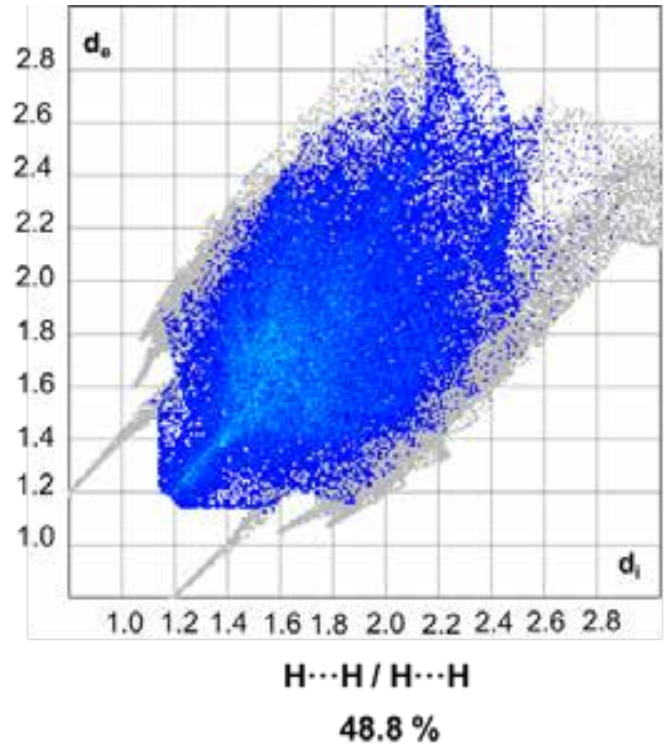

a)

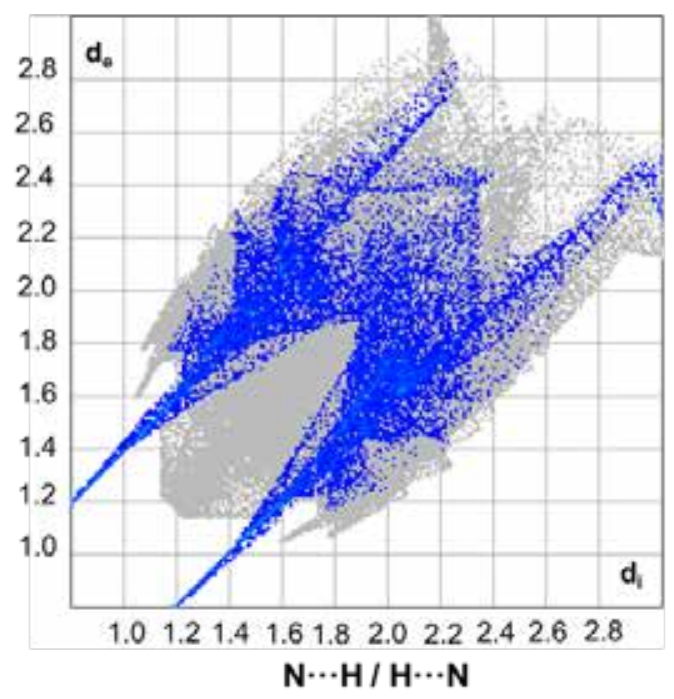

$15.1 \%$

c)

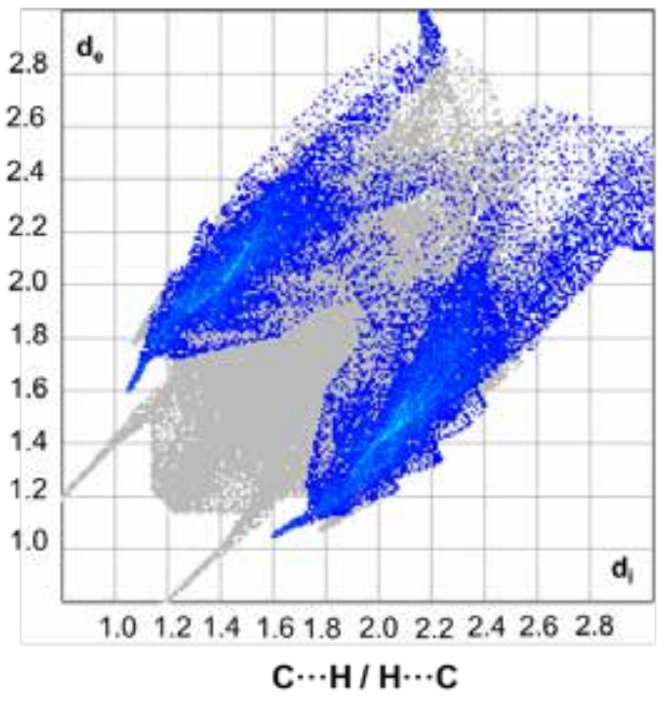

$23.3 \%$

b)

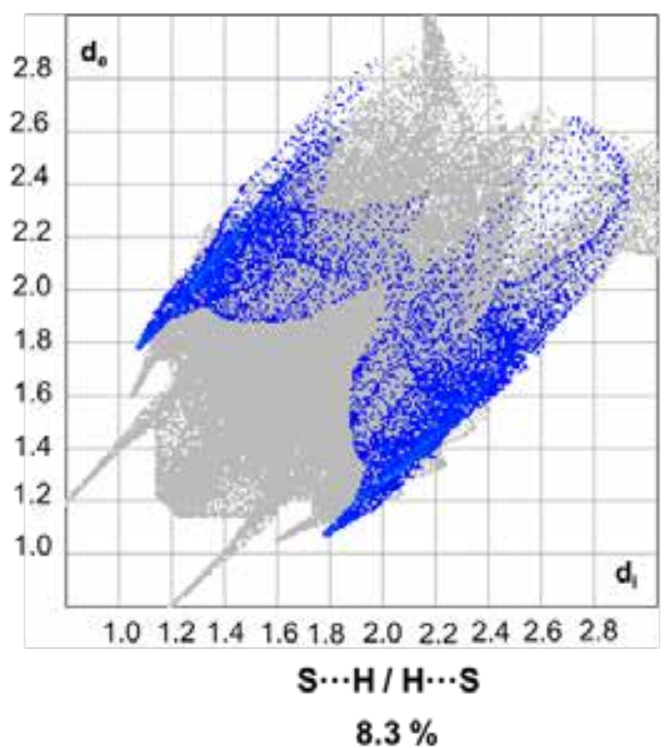

d)

Şekil 7. Toplam Hirsfeld yüzeyine katkıda bulunan etkileşimler

\section{SONUÇ}

Sonuç olarak, 4-(3-metil-3-fenilsiklobütil)2-(2-(piridin-4-ylmetilen)hidrazinil)tiyazol bileşiği sentezlenmiş, kristal ve moleküler yapısı aydınlatılmıştır. Bileşiği oluşturan siklobütan, tiyazol, Schiff bazı ve piridin'e ait yapısal ayrıntılar belirlenmiş ve literatürdeki karşılıkları ile birlikte verilmiştir. Kristal yapıdaki hidrojen bağları ortaya çıkarılmış ve Hirshfeld yüzey analizi yöntemiyle moleküler paketlenme açıklanmıştır.

\section{TEŞEKKÜR}

Kristali şahsıma hediye eden Sayın Prof. Dr. Alaaddin Çukurovalı hocama çok teşekkür ederim.

Bruker D8 QUEST difraktometresinin kullanımı için Sinop Üniversitesi Bilimsel ve Teknolojik Araştırma Uygulama ve Araştırma Merkezi'ne teşekkür ederim. 


\section{KAYNAKLAR}

Abbas I, Gomha S, Elaasser M, Bauomi M, 2015. Synthesis and biological evaluation of new pyridines containing imidazole moiety as antimicrobial and anticancer agents. Turkish Journal of Chemistry, 39: 334-346.

Bachir M, Riffaud J, Lacolle J, Lemoine J, Almeida AD, Houziaux P, Danrée B, 1990. Synthesis and anticonvulsant activity of some 2-(N-substituted glycylamino)-4-methyl thiazoles. European Journal of Medicinal Chemistry, 25 (1):71-74.

Bhardwaj V, Noolvi MN, Jalhan S, Patel HM, 2012. Synthesis, and antimicrobial evaluation of new pyridine imidazo [2,1b]1,3,4-thiadiazole derivatives. Journal of Saudi Chemical Society, 20: S406-S410.

Cankılıç MY, Yurttaş L, 2017. Study on the Antimicrobial Effects of Novel Thiazole Derivatives. Marmara Pharmaceutical Journal, 21(3): 654-659.

Chimenti F, Bizzarri B, Maccioni E, Secci D, Bolasco A, Fioravanti R, Chimenti P, Granese A, Carradori S, Rivanera D, Lilli D, Zicari A, Distinto S, 2007. Synthesis and in vitro activity of 2-thiazolylhydrazone derivatives compared with the activity of clotrimazole against clinical isolates of Candida spp. Bioorganic \& Medicinal Chemistry Letters, 17: 4635-4640.

Dehmlow EV, Schmidt S, 1990. Synthese von stereoisomeren 3-substituierten Cyclobutancarbonsäure-Derivaten. Liebigs Annalen der Chemie, 5: 411-414.

Farrugia LJ, 2012. WinGX and ORTEP for Windows: an update. Journal of Applied Crystallography, 30: 837-838.

Ghasemi B, Sanjarani G, Sanjarani Z, Majidiani H, 2015. Evaluation of anti-bacterial effects of some novel thiazole and imidazole derivatives against some pathogenic bacteria. Iranian Journal of Microbiology, 7(5):281-286.

Gueiffier A, Mavel S, Lhassani M, Elhakmaoui A, Snoeck R, Andrei G, Chavignon O, Teulade J, Witvrouw M, Balzarini J, Clercq E, Chapat J, 1998. Synthesis of Imidazo[1,2-a] pyridines as Antiviral Agents. Journal of Medical Chemistry, 41 (25): 5108-5112.

Hassan FA, 2012. Synthesis, Characterization, Anti-inflammatory, and Antioxidant Activities of Some New Thiazole Derivatives. International Journal of Applied Science and Technology, 2 (7): 180-187.

Inkaya E, Dinçer M, Ekici Ö, Cukurovali A, 2013. 1-(3-Methyl3-mesityl)-cyclobutyl-2-(5-pyridin-4-yl-2H-[1,2,4]triazol3-ylsulfanyl)-ethanone: X-ray structure, spectroscopic characterization and DFT studies. Spectrochimica Acta Part A: Molecular and Biomolecular Spectroscopy, 101:218-227.

Jaishree V, Ramdas N, Sachin J, Ramesh B, 2012. In vitro antioxidant properties of new thiazole derivatives. Journal of Saudi Chemical Society, 16: 371-376.

Joseyphus RS, Nair MS, 2008. Antibacterial and Antifungal Studies on Some Schiff Base Complexes of Zinc(II). Mycobiology, 36(2): 93-98.

Karegoudar P, Karthikeyan MS, Prasad DJ, Mahalinga M, Holla BS, Kumari NS, 2008. Synthesis of some novel 2,4-disubstituted thiazoles as possible antimicrobial agents. European Journal of Medicinal Chemistry, 43: 261-267.
Lesyk R, Vladzimirska O, Holota S, Zaprutko L, Gzella A, 2007. New 5-substituted thiazolo[3,2-b][1,2,4]triazol-6-ones: Synthesis and anticancer evaluation. European Journal of Medicinal Chemistry, 42: 641-648.

Lesyk R, Zimenkovsky B, Atamanyuk D, Jensen F, KiećKononowicz K, Gzella A, 2006. Anticancer thiopyrano[2,3-d] $[1,3]$ thiazol-2-ones with norbornane moiety. Synthesis, cytotoxicity, physico-chemical properties, and computational studies. Bioorganic \& Medicinal Chemistry, 14: 5230-5240.

Liaras K, Geronikaki A, Glamočlija J, Ćirić A, Soković M, 2011. Thiazole-based chalcones as potent antimicrobial agents. Synthesis and biological evaluation. Bioorganic \& Medicinal Chemistry, 19: 3135-3140.

Lu X, Liu X, Wan B, Franzblau SG, Chen L, Zhou C, You Q, 2012. Synthesis and evaluation of anti-tubercular and antibacterial activities of new 4-(2,6-dichlorobenzyloxy)phenyl thiazole, oxazole and imidazole derivatives. Part 2. European Journal of Medicinal Chemistry, 49: 164-171.

Mohamed MS, Awad YEE, El-Hallouty SM, El-Araby M, Design, 2012. Synthesis and Cancer Cell Line Activities of Pyrazolo[3,4-b]pyridine Derivatives. Open Journal of Medicinal Chemistry, 2: 78-88.

Narayana B, Vijaya Raj KK, Ashalatha BV, Kumari NS, Sarojini BK, 2004. Synthesis of some new 5-(2-substituted-1,3-thiazol5-yl)-2-hydroxy benzamides and their 2-alkoxy derivatives as possible antifungal agents. European Journal of Medicinal Chemistry, 39: 867-872.

Nardelli M, 1995. PARST95 - an update to PARST: a system of Fortran routines for calculating molecular structure parameters from the results of crystal structure analyses. Journal of Applied Crystallography, 28:659.

Pradhan J, Goyal A, 2016. Synthesis, anticonvulsant activity and QSAR studies of some new pyrazolyl pyridines. Medical Chemistry Research, 25(8): 1639-1656.

Prasad AVGS, Trinagaraju K, Rao BG, Usha Y, Reddy PS, Rao PV, 2013. Synthesis and Biological Activity Of Aniline Derivative Schiff Bases. International Journal of Innovative Research \& Development, 2(10): 97-102.

Rajput CS, Sharma S, Yashovardhan, 2011. Synthesis of New Pyridine Derivatives as potent antifungal agents. International Journal of Pharma and Bio Sciences. 2(3): 200-209.

Salam OIA, Al-Omar MA, Khalifa NM, Amr AEE, Abdallah MM, 2013. Analgesic and Anticonvulsant Activities of Some Newly Synthesized Trisubstituted Pyridine Derivatives. Zeitschrift für Naturforschung, 68:264-268.

Saravanan G, Alagarsamy V, Prakash C R, Kumar PD, Selvam TP, 2011. Synthesis of Novel Thiazole Derivatives as Analgesic Agents. Asian Journal of Research in Pharmaceutical Sciences, 1(4): 134-138.

Şen F, Dinçer M, Cukurovali A, 2015. Structural and spectroscopic characterization of 4-(3-methyl-3-phenylcyclobutyl)-2-(2propylidenehydrazinyl)thiazole: A combined experimental and DFT analysis. Spectrochimica Acta Part A: Molecular and Biomolecular Spectroscopy, 150: 257-267. 
Şen F, Efil K, Bekdemir Y, Dinçer M, 2017. Structural, spectroscopic characterization of (E)-4-chloro-2-((4-methoxybenzylidene) amino)phenol as potential antioxidant compound. Journal of Molecular Structure, 1127: 645-652.

Sheldrick GM, 1997. SHELXL-97; Program for Crystal Structures Refinement, University of Gottingen.

Sheldrick GM, 1997. SHELXS-97; Program for the Solution of Crystal Structures, University of Gottingen.

Silva MC, Silva LD, Modolo LV, Alves RB, Resende AM, Martins VBC, Fátima A, 2011. Schiff bases: A short review of their antimicrobial activities. Journal of Advanced Research, 2 (1): $1-8$.

Solomons G, Fryhle C, 2000. Organic Chemistry (Seventh Edition), John Wiley \& Sons, Inc., New York.

Spackman M, Jayatilaka D, 2009. Hirshfeld surface analysis. Crystal Engineering Communication, 11: 19-32.

Spackman M, McKinnona JJ, 2002. Fingerprinting intermolecular interactions in molecular crystals. Crystal Engineering Communication, 4: 378-392.

Spek AL, 2009. Structure validation in chemical crystallography. Acta Crystallographica Section D: B1ological Crystallography, D65: 148-155.
Stoe \& Cie, X-AREA (Version 1.18) X-RED32 (Version 1.04), Stoe \& Cie, Darmstadt, Germany, 2002.

Thore SN, Gupta SV, Baheti KG, 2013. Docking, synthesis, and pharmacological investigation of novel substituted thiazole derivatives as non-carboxylic, anti-inflammatory, and analgesic agents. Medicinal Chemistry Research, 22: 38023811 .

Turner M J, McKinnon J J, Wolff S K, Grimwood D J, Spackman P R, Jayatilaka D, Spackman M A, 2017. CrystalExplorer17. University of Western Australia.

Utreja D, Vibha, Singh S, Kaur M, 2015. Schiff Bases and their Metal Complexes as Anti-Cancer Agents: A Review. Current Bioactive Compounds, 11(4): 215-230.

Zhou X, Shao L, Jin Z, Liu J, Dai H, Fang J, 2007. Synthesis and Antitumor Activity Evaluation of Some Schiff Bases Derived from 2-Aminothiazole Derivatives. Heteroatom Chemistry, 18(1): 55-59. 